\title{
Aberrant expression of long noncoding RNA PVT1 and its diagnostic and prognostic significance in patients with gastric cancer
}

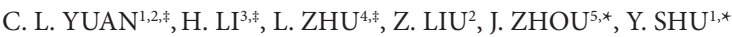 \\ ${ }^{1}$ Department of Oncology, the First Affiliated Hospital of Nanjing Medical University, No. 300 Guangzhou Road, Nanjing 210029, Jiangsu Province, \\ People's Republic of China; ${ }^{2}$ Department of Oncology, The First People's Hospital of Lianyungang, Lianyungang 222002, Jiangsu Province, P.R. \\ China; ${ }^{3}$ Department of Pathology, the Affiliated Hospital of Nanjing University of TCM, Nanjing, Jiangsu, P.R. China; ${ }^{4}$ Department of clinical \\ laboratory, the First People's Hospital of Lianyungang, Lianyungang, Jiangsu, P.R. China; ${ }^{5}$ Department of Molecular Cell Biology and Toxicology, \\ School of Public Health, Nanjing Medical University, 140 Hanzhong Road, Nanjing 210029, Jiangsu Province, People’s Republic of China
}

*Correspondence author: jwzhou@njmu.edu.cn,yongqian_shu@163.com

${ }^{*}$ Contributed equally to this work.

Received August 25, 2015 / Accepted November 26, 2015

\begin{abstract}
Emerging evidences indicate that dysregulated long noncoding RNAs (lncRNAs) are implicated in cancer tumorigenesis and progression and might be used as diagnosis and prognosis biomarker, or potential therapeutic targets. LncRNA PVT1 has been reported to be upregulated in diverse human cancers; however, its clinical significance in gastric cancer (GC) remains elusive. This study was to evaluate the expression of PVT1 in GC and further explore its clinical significance.Previous microarray datasets were analyzed to conduct a preliminary screening for candidate lncRNAs of gastric cancer biomarkers in human gastric cancer tissues. Expression levels of PVT1 in 111pairs of gastric cancer and adjacent normal tissues, gastric cancer cell lines and gastric cancer juices compared to their corresponding controls were detected by real-time quantitative RT-PCR assay. A receiver operating characteristic (ROC) curve and Kaplan-Meier analysis were constructed to evaluate the diagnostic and prognostic values. Univariate and multivariate analysis were performed using the Cox proportional hazard analysis.PVT1 expression was remarkably increased in gastric cancer tissues and cell lines compared with that in the normal control, and its up-regulation was significantly correlated to invasion depth $(P<0.001)$, advanced TNM stage $(P=0.002)$ and regional lymph nodes metastasis $(P<0.001)$ in gastric cancer. $P V T 1$ levels were robust in differentiating gastric cancer tissues from controls [area under the curve $(\mathrm{AUC})=0.728$; $95 \%$ confidence interval $(\mathrm{CI})=0.665-0.786$, $\mathrm{p}<0.01$ ]. KaplanMeier analysis demonstrated that increased $P V T 1$ expression contributed to poor overall survival $(P<0.01)$ and disease-free survival $(P<0.01)$ of patients. A multivariate survival analysis also indicated that $P V T 1$ could be an independent prognostic marker. The levels of $P V T 1$ in gastric juice from gastric patients were significantly higher than those from normal subjects $(P=0.03)$. PVT1 might serve as a promising biomarker for early detection and prognosis prediction of gastric cancer.
\end{abstract}

Key words: long noncoding RNA, PVT1, gastric cancer, clinical relevance

Gastric cancer is the fourth most common malignancy in the world and is the second most frequent cause of cancerrelated deaths worldwide, with particularly high incidence in East Asian [1,2]. Although gastric endoscopy have contributed to this reduction by enabling early diagnosis gastric cancer, most patients are diagnosed in the advanced stage and have poor prognosis [3]. The clinical stage, based on the TNM classification system, at the time of diagnosis is currently the most important prognostic factor, and the molecular mechanism involved in progression and metastasis of gastric cancer remains unclear [4]. Thus, novel findings on diagnosis and prognosis factors for gastric cancer would be of great clinical relevance.

Recent advances in whole-genome sequencing technology have contribute to the detection of a new type of regulation gene, long noncoding RNAs (lncRNAs), which are more than 200 bases in length and unable to be translated into proteins. Emerging evidence suggests that lncRNAs may play critical roles in cellular development, differentiation, and many other biological processes. Many studies have revealed that the deregulated expression of lncRNAs plays a functional role in a variety of disease states $[5,6]$. Recently, the functions of some 
of the lncRNAs have been reported as regulators in different tumors [7-9]. For example, HOTAIR, which is one of the few well-studied lncRNAs, plays a significant role in tumor progression by regulation of oncogene or tumor suppressor gene expression through binding to PRC2 [7]. In addition, metastasis-associated lung ade-nocarcinoma transcript 1 (MALAT1) facilitated renal cell carcinoma aggressive through Ezh2 and interacts with miR-205 [10]. Recently, multiple lines of evidences link dysregulation of lncRNAs to gastric cancer, such as HOTAIR, MALAT1, maternally expressed gene 3 (MEG3) and growth arrest-specific 5 (GAS5) [11-13]. Functional lncRNAs can be used for cancer diagnosis and prognosis, and serve as potential therapeutic targets; thus, lncRNAs can be considered as a new diagnostic and therapeutic gold mine in cancer [ 14].

The human PVT1 gene (also known as PVT1 oncogene) is a long intergenic noncoding RNA (lincRNA) homologous to the mouse plasmacytoma variant translocation gene (PVT1), is locate on chromosome 8q24.21, which does not encode for protein but encodes for a $1.7 \mathrm{~kb}$ noncoding RNA. Currently, several studies have shown that $P V T 1$ is overexpressed in tumors and functions as an oncogene gene, including colorectal cancer [15], serous ovarian and breast cancers [16], and has been associated with reduced survival duration in patients. Recent studies have also showed that PVT1 is upregulated in human gastric carcinomas [17]. However, the overall clinical role of PVT1 in GC has not yet been well characterized.

In this study, we uncovered that $P V T 1$ expression was upregulated in gastric cancer tissues and cell lines. High expression of PVT1 was associated with clinicopathological characteristics and poor prognosis in gastric cancer patients. We also determined its prognostic role in GC, which might dramatically improve the therapeutic strategy of GC.

\section{Materials and methods}

Computational analysis. One human microarray datasets (GSE51575) were downloaded from GEO database and background adjusted using Robust Multichip Average. GATExplorer was used to process microarrays on a local computer for gene expressions of lncRNAs [18]. This GATExplorer provides a series of R packages, designed to be used with BioConductor tools, that allow to apply in a simple way the probe mapping data included in GATExplorer. A type of files called ncRNA Mapper were also obtained from GATExplorer, which include the probes that do not map to any coding region but that were mapped to a database for non-coding RNA of human and mouse derived from RNAdb [19]. A customized R scripts was used to perform a microarray expression calculation according to the re-mapping data (file ncrnamapperhgu133plus2cdf_3.0) obtained from public database NCBI.

Cell lines. Human gastric adenocarcinoma cancer cell lines SGC7901, BGC823, MGC803, AGS and MKN45 and the normal gastric epithelium cell line (GES1) were obtained from the Chinese Academy of Sciences Committee on Type Culture
Collection cell bank (Shanghai, China). MGC803, AGS and BGC823 cells were cultured in RPMI 1640; MKN45, GES-1 and SGC7901 cells were cultured in DMEM (GIBCO-BRL) medium supplemented with $10 \%$ fetal bovine serum (FBS), $100 \mathrm{U} / \mathrm{ml}$ penicillin and $100 \mathrm{mg} / \mathrm{ml}$ streptomycin (Invitrogen, Carlsbad, CA, USA) at $37^{\circ} \mathrm{C}$ in $5 \% \mathrm{CO}_{2}$.

Tissue samples and clinical data collection. In this study, we analyzed 111 patients who underwent resection of the primary gastric cancer at the First Affiliated Hospital of Nanjing Medical University and Yangzhou No.1 People's hospital. The study was approved by the Ethics Committee on Human Research of the First Affiliated Hospital of Nanjing Medical University and Yangzhou No.1 People's hospital, and written informed consent was obtained from all patients. The clinicopathological characteristics of the gastric cancer patients are summarized in Table 2. All patients with gastric cancer have been followed up at intervals of 1-2 months until September 2014, and the median follow-up period was 36 months (range, $20-48$ months). Followup studies included physical examination, laboratory analysis, and computed tomography if necessary. OS was defined as the interval between the dates of surgery and death. DFS was defined as the interval between the dates of surgery and recurrence; if recurrence was not diagnosed, patients were censored on the date of death or the last follow-up.

Gastric juices were collected from 56 subjects, including 33 patients with gastric cancer (mean age, $60.3 \pm 9.8$ years) and 23 cases with normal mucosa or minimal gastritis (mean age, $55.6 \pm 11.5 y e a r s$ ) between July 2012 and November 2013 in the Endoscopy Center of the First Affiliated Hospital of Nanjing Medical University. For each case, the diagnosis was confirmed by endoscopic examination followed by pathological diagnosis of biopsies. Cases with normal mucosa or minimal gastritis, which had no family history of gastric cancer, were treated as the controls. Gastric juice specimens were centrifuged at $2,000 \times \mathrm{g}$ for $30 \mathrm{~min}$ at $4{ }^{\circ} \mathrm{C}$ to remove cell fragments and mucus. Then, the $\mathrm{pH}$ was measured using a glass electrode $\mathrm{pH}$ meter. Finally, the supernatants were stored at $-80{ }^{\circ} \mathrm{C}$ until use. The study protocol was approved by the Ethics Committee of the First Affiliated Hospital of Nanjing Medical University. All specimens were handled and made anonymous following the ethical and legal standards.

RNA preparation and quantitative real-time PCR. Total RNAs were extracted from tumorous and adjacent normal tissues or cultured cells using Trizol reagent (Invitrogen) following the manufacturer's protocol. For gastric juice RNA extraction, $750 \mu \mathrm{l}$ Trizol LS reagent (Invitrogen) was mixed with $250 \mu \mathrm{l}$ gastric juice. After vortex mixing for $30 \mathrm{~s}$ and then standing for $5 \mathrm{~min}, 200 \mu \mathrm{l}$ chloroform was added. The Trizol-chloroform mixture was vortex-mixed for $15 \mathrm{~s}$ and then centrifuged at $12,000 \times \mathrm{g}$ for $15 \mathrm{~min}$ at $4{ }^{\circ} \mathrm{C}$. The upper aqueous phase was transferred to a fresh tube. Finally, RNA was extracted following the manufacturer's instructions. Total RNA was quantified using a SmartSpec Plus spectrophotometer (Bio-Rad, Hercules, CA, USA). The A260/A280 ratio was used to evaluate RNA purity. RT and qPCR kits (Takara, Dalian, 


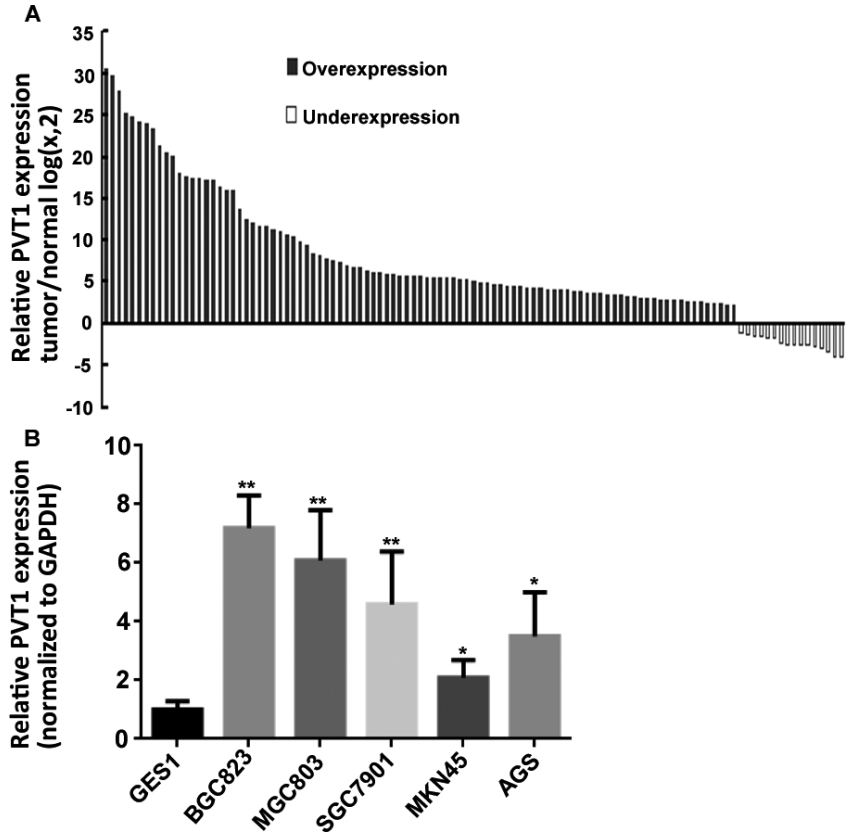

Figure 1. A. Relative expression of PVT1 in five gastric cancer cell lines (SGC7901, BGC823, MGC803, AGS and MKN45) and human normal gastric epithelial cell line (GES1) analyzed by quantitative RT-PCR $\left({ }^{*} \mathrm{p}<0.05\right.$, $\left.{ }^{* *} \mathrm{p}<0.01\right)$. B. Relative expression of $P V T 1$ in gastric cancer tissues and adjacent normal tissues.

China) were used to evaluate the expression of PVT1 in tissue samples, cultured cells and gastric juice. The primers used for glyceraldehyde 3-phosphate dehy-drogenase (GAPDH) and PVT1 were as follows: 5'-TACAACCACTGCACTACCTG-3' (sense) and 5'-TGTTGCTGTAGCCAAATTCGTT-3' (antisense) for GAPDH. The primer sequences were

Table 1. Fifteen candidate lncRNAs expressed with more than 2.5 fold changes higher compared with corresponding non-tumor tissues

\begin{tabular}{lccc}
\hline Fold change & P Value & FDR value & GeneName \\
\hline 5.2 & $<0.001$ & $<0.001$ & PVT1 \\
4.5 & $<0.001$ & $<0.001$ & UCA1 \\
4.8 & $<0.001$ & $<0.001$ & H19 \\
4.4 & $<0.001$ & 0.003269372 & HOXA11-AS \\
4.0 & $<0.001$ & $<0.001$ & LOC100131046 \\
3.3 & 0.006 & 0.02 & BCAR4 \\
3.2 & $<0.001$ & $<0.001$ & LINC00152 \\
2.8 & 0.0055 & 0.019 & ANKRD30BP2 \\
2.6 & $<0.001$ & $<0.001$ & KRT16P2 \\
2.5 & $<0.001$ & $<0.001$ & HMGB3P1 \\
2.3 & $<0.001$ & $<0.001$ & SNHG15 \\
2.2 & $<0.001$ & $<0.001$ & SNHG7 \\
2.2 & $<0.001$ & $<0.001$ & HOTAIR \\
2.2 & $<0.001$ & $<0.001$ & SPRR2C \\
2.0 & $<0.001$ & $<0.001$ & MAFG-AS1 \\
\hline
\end{tabular}

5'- TGAGAACTGTCCTTACGTGACC-3' (sense) and 5'AGAGCACCAAGACTGGCTCT-3' (antisense) for PVT1. Real-time PCR was performed in triplicate, and the relative expression of PVT1 was calculated using the comparative cycle threshold (CT) $\left(2^{-\Delta \Delta C T}\right)$ method with glyceraldehyde3-phosphate dehydrogenase $(\mathrm{GAPDH})$ as the endogenous control to normalize the data, and the relative amount in gastric juice of PVT1 to GAPDH RNA was calculated using the Equation $2^{-\Delta \mathrm{CT}}$, where $\Delta \mathrm{CT}=\left(\mathrm{CT}_{P V T 1}-\mathrm{CT}_{\mathrm{GAPDH}}\right)$.

Statistical analysis. All statistical analyses were performed using SPSS 20.0 software (IBM, SPSS, Chicago, IL, USA). The significance of the differences between groups was estimated by the Student t-test, $\chi 2$ test, or Wilcoxon test, as appropriate. DFS and $O S$ rates were calculated by the Kaplan-Meier method with the log-rank test applied for comparison. Survival data were evaluated using univariate and multivariate Cox proportional hazards models. Variables with a value of $\mathrm{P}<0.05$ in univariate analysis were used in subsequent multivariate analysis on the basis of Cox regression analyses. Receiver operating characteristic (ROC) curves were constructed to evaluate the diagnostic value of PVT1 levels, by plotting sensitivity versus $100 \%$ specificity. Two-sided p-values were calculated, and a probability level of 0.05 was chosen for statistical significance.

\section{Results}

Microarray analysis. A total of $125 \mathrm{lncRNAs}$ were altered expressed more than two folds in gastric cancer tissues identified from the microarrays. Twenty-eight of the upregulated lncRNAs had an obvious fold change in the gastric cancer tissues when compared with corresponding non-tumortissues (Table 1). PVT1 expression levels in the gastric cancer tissues were the 5.2 times higher than those in the corresponding non-tumor tissues (Table 1). Based on these results and recent discoveries concerning the role of PVT1 in tumorigenesis, we studied the expression of $P V T 1$ further in patients with gastric cancer and its correlation with clinical features.

$P V T 1$ was upregulated in tissues and cell lines. PVT1 expression levels were investigated in 111 paired gastric cancer samples and adjacent histologically normal tissues using quantitative polymerase chain reaction (qPCR) assays. PVT1 expression was significantly higher in tumor tissues compared with adjacent normal tissues $(P<0.01$; Fig. 1A). qRT-PCR assays were further developed to quantify PVT1 in gastric cancer cell lines, including MGC803, BGC823, MKN45, SGC7901, AGS and the normal gastric epithelium cell line GES1. A significant high PVT1 expression was found in SGC7901, BGC823, MGC803, AGS and MKN45 compared to GES-1 (Fig. 1B).

$P V T 1$ expression and clinicopathological factors in gastric cancer. To assess the correlation of PVT1 expression with clinicopathological data, PVT1 expression levels in tumor tissues were categorized as low or high in relation to the median value of relative PVT1 expression (5.22-fold, tumors/noncancerous). Clinicopathological factors were 
analyzed in the high and low PVT1 expression groups. As shown in Table 1, the high PVT1 group $(\mathrm{n}=55)$ showed higher invasion depth $(P<0.001)$, advanced TNM stage $(P=$ $0.002)$ and regional lymph nodes metastasis $(P<0.001)$ than the lower PVT1 expression group $(\mathrm{n}=56)$. However, there was no significant correlation between PVT1 expression and other clinicopathological features, such as age, gender, tumor

Table 2. Correlation between PVT1 expression and clinicopathological characteristics of gastric cancer

\begin{tabular}{|c|c|c|c|}
\hline \multirow[t]{2}{*}{ Clinical parameter } & \multicolumn{2}{|l|}{ PVT1 } & \multirow{2}{*}{$\begin{array}{l}\text { Chi-squarec } \\
\text { test P-value }\end{array}$} \\
\hline & $\begin{array}{l}\text { High No. } \\
\text { cases }(\mathrm{n}=55)\end{array}$ & $\begin{array}{c}\text { Low No. } \\
\text { cases }(\mathrm{n}=56)\end{array}$ & \\
\hline Age (years) & & & 0.507 \\
\hline$<50$ & 29 & 26 & \\
\hline$>50$ & 26 & 30 & \\
\hline Gender & & & 0.362 \\
\hline Male & 37 & 33 & \\
\hline Female & 18 & 23 & \\
\hline Location & & & 0.985 \\
\hline Distal & 21 & 21 & \\
\hline Middle & 22 & 22 & \\
\hline Proximal & 12 & 13 & \\
\hline Size & & & 0.768 \\
\hline$>5 \mathrm{~cm}$ & 31 & 30 & \\
\hline$<5 \mathrm{~cm}$ & 24 & 26 & \\
\hline Histologic differentiation & & & 0.058 \\
\hline Well & 13 & 26 & \\
\hline Moderately & 25 & 14 & \\
\hline Poorly & 8 & 8 & \\
\hline Undifferentiated & 9 & 8 & \\
\hline Invasion depth & & & $<0.001^{\star}$ \\
\hline $\mathrm{T} 1$ & 4 & 21 & \\
\hline $\mathrm{T} 2$ & 9 & 23 & \\
\hline $\mathrm{T} 3$ & 25 & 7 & \\
\hline $\mathrm{T} 4$ & 17 & 5 & \\
\hline TNM Stages & & & $0.002^{*}$ \\
\hline I & 4 & 19 & \\
\hline II & 22 & 23 & \\
\hline III & 27 & 13 & \\
\hline IV & 2 & 1 & \\
\hline Lymphatic metastasis & & & $0.029^{*}$ \\
\hline Yes & 30 & 19 & \\
\hline No & 25 & 37 & \\
\hline Regional lymph nodes & & & $<0.001^{*}$ \\
\hline PNO & 25 & 37 & \\
\hline PN1 & 4 & 10 & \\
\hline PN2 & 16 & 4 & \\
\hline PN3 & 10 & 5 & \\
\hline Distant metastasis & & & 0.618 \\
\hline Yes & 2 & 1 & \\
\hline No & 53 & 55 & \\
\hline
\end{tabular}
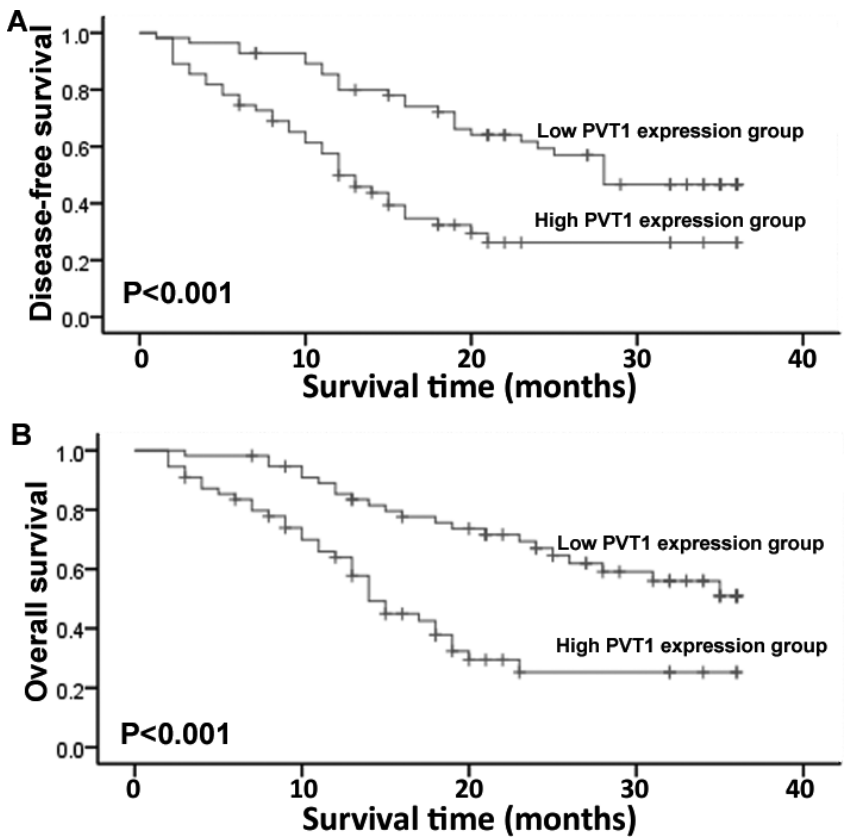

Figure 2. Kaplan-Meier overall survival curves of gastric cancer patients according to the level of $P V T 1$ expression. A. Disease-free survival of patients with gastric cancer based on PVT1 expression status $(\mathrm{p}<0.001$, log-rank) B. Overall survival of patients with gastric cancer based on PVT1 expression status ( $\mathrm{p}<0.001, \log -$ rank).

location, tumor size, histologic grade, and distant metastasis $(P>0.05)$.

High PVT1 expression is associated with poor prognosis of patients with gastric cancer. Kaplan-Meier analysis and log-rank test were used to evaluate the effects of PVT1 expression and the clinicopathological characteristics on disease-free survival (DFS) and overall survival (OS). The results showed that patients in the high PVT1 expression group had a higher recurrence rate (median DFS: 12 months) and much shorter overall survival (median OS: 14 months) than those in the low PVT1 expression group (median DFS: 26months; median OS: 28 months; $\mathrm{p}<0.01$ and $<0.01$, respectively; Fig. $2 \mathrm{~A}, 2 \mathrm{~B}$ ). The 3 -year DFS and OS were $26.2 \%$ and $25.3 \%$, respectively, in the high PVT1 expression group, and $46.6 \%$ and $50.9 \%$, respectively in the low $P V T 1$ expression group. Univariate analyses of clinical variables considered as potential predictors of survival are shown in Table 2. Further analysis in a multivariate Cox proportional hazards model showed that PVT1 expression, together with TNM stage, was strongly associated with DFS and OS. PVT1 expression was an independent prognostic indicator of DFS (hazard ratio $[\mathrm{HR}]=2.210 ; 95 \%$ confidence interval $[\mathrm{CI}], 1.111-4.395 ; P=0.024$ ) and OS (hazard ratio $[\mathrm{HR}]=2.280 ; 95 \%$ confidence interval $[\mathrm{CI}], 1.054-4.930 ; P=$ 0.036 ) in patients with gastric cancer (Table 3 ).

Observation of the diagnostic value of using PVT1 as a marker. We observed whether PVT1 could be used as a gastric cancer marker. We used corresponding adjacent 

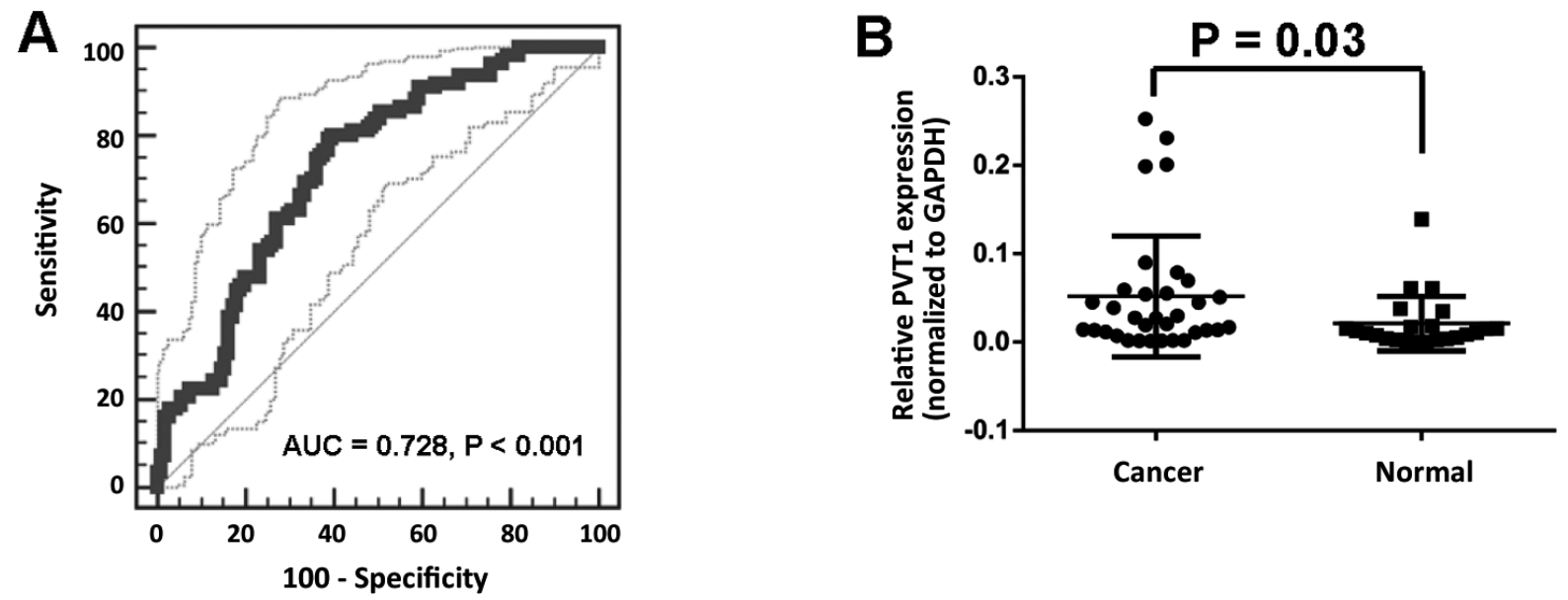

Figure 3. A. Receiver operation characteristics (ROC) curve of using PVT1 for differentiating gastric cancer tissues from normal tissues. The area under the ROC curve (AUC) is up to 0.728. B. Relative expression of PVT1 from gastric cancer patients and normal subjects in gastric juice. The relative amount $P V T 1$ to GAPDH RNA was calculated using the Equation $2^{-\Delta C \mathrm{~T}}$, where $\Delta \mathrm{CT}=\left(\mathrm{CT}_{P V T 1}-\mathrm{CT}_{\mathrm{GAPDH}}\right)$. P values indicated significant differences between specimens determined by $t$ test.

non-tumorous tissues as a control to produce a ROC curve. The cutoff value was $4.46(\triangle \mathrm{Ct}$ value). The area under the ROC curve was 0.728; (95\% CI $=0.665-0.786, P<0.001$; Fig. 3A). The sensitivity and specificity was 0.802 and 0.604 , respectively. The Youden index of PVT1 was 0.406 .

Gastric juice is a simple and easy-to-obtain sample which can provide available information in the diagnosis of gastric cancer. To evaluate the diagnostic value of PVT1, the levels of gastric juice $P V T 1$ were detected in gastric juice between
GC patients and normal cases. Interestingly, we found that $P V T 1$ levels in gastric juice from patients with gastric cancer were significantly higher than those from normal subjects ( $\mathrm{p}$ $=0.03$, Fig. 3B).

\section{Discussion}

Accumulation evidence suggests that cancer lncRNAs, similar to protein-coding genes, may perform as oncogenic

Table 3. Univariate and multivariate Cox regression analyses $P V T 1$ for DFS or OS of patients in study cohort $(\mathbf{n}=111)$.

\begin{tabular}{|c|c|c|c|c|c|c|}
\hline \multirow[t]{2}{*}{ Variables } & \multicolumn{3}{|c|}{ DFS } & \multicolumn{3}{|c|}{ OS } \\
\hline & HR & $95 \%$ CI & $\mathrm{p}$ value & HR & $95 \%$ CI & $\mathrm{p}$ value \\
\hline \multicolumn{7}{|l|}{ Univariate analysis } \\
\hline Age(<50years vs. $>50$ years $)$ & 0.814 & $0.496-1.335$ & 0.414 & 0.874 & $0.519-1.470$ & 0.611 \\
\hline Gender(male vs. female) & 0.806 & $0.479-1.354$ & 0.414 & 0.765 & $0.441-1.329$ & 0.342 \\
\hline Location(Distal vs. Middle+ Proximal) & 1.100 & $0.655-1.846$ & 0.719 & 0.864 & $0.509-1.467$ & 0.588 \\
\hline tumor size $(>5 \mathrm{~cm}$ vs. $<5 \mathrm{~cm})$ & 0.908 & $0.554-1.489$ & 0.703 & 0.936 & $0.556-1.574$ & 0.802 \\
\hline Histologic differentiation(Well+ Moderately vs. Poorly+ Undifferentiated) & 1.479 & $0.880-2.486$ & 0.140 & 1.464 & $0.848-2.526$ & 0.171 \\
\hline Invasion depth(T3+T4 vs. T1+T2) & 1.727 & $1.047-2.849$ & $0.032^{*}$ & 1.949 & $1.146-3.312$ & $0.014^{*}$ \\
\hline TNM stage (III + IV vs. I+II) & 2.455 & $1.478-4.076$ & $0.001^{*}$ & 2.840 & $1.661-4.857$ & $<0.001^{*}$ \\
\hline Lymphatic metastasis(No vs. Yes) & 0.613 & 0.373-1.009 & 0.054 & 0.601 & $0.355-1.016$ & 0.057 \\
\hline Regional lymph nodes(PN2+ PN3 vs. PN0+ PN1) & 1.678 & $0.987-2.854$ & 0.056 & 2.056 & $1.185-3.567$ & $0.010^{*}$ \\
\hline Distant metastasis(No vs. Yes) & 0.338 & $0.104-1.100$ & 0.072 & 0.268 & $0.082-0.877$ & $0.030^{*}$ \\
\hline Expression of $P V T 1$ (High vs. Low) & 2.563 & $1.532-4.290$ & $<0.001^{*}$ & 1.572 & $1.210-2.042$ & $0.001^{*}$ \\
\hline \multicolumn{7}{|l|}{ Multivariate analysis } \\
\hline TNM stage (I+II vs. III + IV) & 2.059 & $1.217-3.483$ & $0.007^{\star}$ & 2.589 & $1.401-4.784$ & $0.002^{*}$ \\
\hline Invasion depth(T3+T4 vs. T1+T2) & 0.994 & $0.517-1.910$ & 0.985 & 1.274 & $0.605-2.683$ & 0.524 \\
\hline Regional lymph nodes(PN0+ PN1vs. PN2+ PN3) & & & & 0.761 & $0.371-1.562$ & 0.456 \\
\hline Distant metastasis(No vs. Yes) & & & & 0.313 & $0.088-1.117$ & 0.074 \\
\hline Expression of PVT1 (High vs. Low) & 2.210 & $1.111-4.395$ & $0.024^{*}$ & 2.280 & $1.054-4.930$ & $0.036^{*}$ \\
\hline
\end{tabular}


or tumor-suppressing factors and may be a new class of cancer biomarkers and therapeutic targets [20-22]. PCGEM1 overexpression and PRNCR1 have been identified for their involvement in prostate carcinogens [23,24] . Reportedly, the IncRNA MALAT-1 has been reported to promote cell motility in non small cell lung carcinoma [25]. The IncRNA HOTAIR induces invasive and metastatic behavior in pancreatic cancer [26]. Recent findings have suggested that many lncRNAs play pivotal roles in GC development. Some lncRNAs, such as GAS5, MEG3, and FENDRR, were reported to regulate proliferation and/or apoptosis and/or metastasis in GC cells $[12,13,27-29]$. These findings suggested that lncRNAs might play a crucial role in carcinogenesis and have a great impact on clinical application.

Current studies revealed an oncogenic role for PVT1 in the pathophysiology of breast and ovarian cancer by virtue of PVT1-mediated inhibition of apoptosis and increasing of proliferation [16]. Recent Nature paper uncovered that PVT1 controls levels of MYC through regulation of the protein stability and they both cooperate to promote cell proliferation in cancer, and the authors analyzed copy number variation data from two large cancer databases (i.e., Progenetix and TCGA) and consistently observed ( $98 \%$ of cases) a cogain of MYC and $P V T 1$ across a wide variety of cancers including GC with ampliied 8q24 region [30]. Numerous studies indicate that $P V T 1$ may play a key role in tumorigenesis and could contribute to tumor progression and aggressiveness. PVT1 was found to be upregulated in cancer compared to noncancerous tissues in various cancer tissues including breast [16], ovarian [31], hepatocellular [32], colorectal [15], and lung [30] cancers, and this upregulation was associated with a worse prognosis in a panel of HCC and colorectal patients. Mechanism investigation showed that the upregulated PVT1 could induce cell cycle genes and activation of the TGF $\beta 1$ signaling pathway and a possible feedback loop between PVT1 and TGF $\beta 1$ existed [32]. However, the precise clinical significance in gastric cancer remains less understood.

We first analyzed previous microarray datasets (GSE51575) to detect the differentially expressed lncRNAs between GC and paired non-tumor tissues, and found that PVT1 was remarkable upregulated in GC tissues. Then, we performed RT-qPCR to investigate whether PVT1 was altered in 111 pairs of gastric cancer tissues and adjacent normal tissues. Results showed that the expression level of PVT1 was increased in GC compared with that in adjacent normal specimens. Additionally, PVT1 expression is markedly increased in gastric cancer cell lines compared with normal gastric epithelium cell line. An ROC curve was constructed for differentiating GC tissues from normal tissues, and the results indicated that the AUC was 0.728. Gastric juice PVT1 levels in gastric cancer patients were further found to be significantly higher than those of normal subjects. Our results provided evidence that expression level of $P V T 1$ was up-regulated in human GC. These findings indicated that PVT1 may play a pivotal role in GC development.
To further determine the clinical significance of PVT1, the association between PVT1 expression and clinicopathological parameters in gastric cancer tissues was analyzed. The results revealed that high PVT1 expression was more frequently detected in tumors with deeper invasion depth, more lymphatic metastasis and advanced TNM stage. Since the clinicopathological parameters of depth of invasion, regional lymph nodes status and tumor stage represent partially the deterioration and progress of GC, PVT1 might be involved in the tumorigenesis and progression of gastric cancer. This association is consistent with previous findings in GC, which also found that PVT1 could promote gastric cancer cell proliferation [33].Kaplan-Meier analysis and logrank test were performed to confirm the prognostic value of $P V T 1$. Our results showed that patients with a high expression of $P V T 1$ seemed to have shorter overall and disease-free survival than patients with lower levels. Furthermore, multivariate Cox analysis showed that PVT1 could serve as an independent prognostic biomarker. Therefore, PVT1 might serve to identify high-risk individual patients with GC who have higher risk of death and, thus, are good candidates for receiving more aggressive treatment.

In conclusion, we demonstrated that $P V T 1$ was significantly up-regulated in GC tissues and some GC cell lines. Its level was associated with tumor progression and poor prognosis. Our data also implied that PVT1 might be capable of distinguishing between cancerous and non-cancerous conditions by examining the expression of $P V T 1$ in tissues and gastric juices. In addition, the high risk of recurrent GC might be predicted by evaluating PVT1 expression in GC samples collected. These findings suggested that $P V T 1$ might be useful as a diagnostic and prognostic biomarker for GC and might be a possible target for diagnosis and gene therapy. However, larger clinical and prospective studies will need to be performed to confirm these preliminary results.

\section{References}

[1] MOORE MA, ATTASARA P, KHUHAPREMA T, LE TN, NGUYEN TH et al. Cancer epidemiology in mainland SouthEast Asia - past, present and future. Asian Pac J Cancer Prev 2010; 11: 67-80.

[2] JEMAL A, SIEGEL R, XU J, WARD E. Cancer statistics, 2010. CA Cancer J Clin 2010; 60: 277-300. http://dx.doi. org/10.3322/caac.20073

[3] SAPARI NS, LOH M, VAITHILINGAM A, SOONG R. Clinical Potential of DNA Methylation in Gastric Cancer: A Meta-Analysis. Plos One 2012; 7.

[4] MILNE AN, CARNEIRO F, O'MORAIN C, OFFERHAUS GJA. Nature meets nurture: molecular genetics of gastric cancer. Human Genetics 2009; 126: 615-628. http://dx.doi. org/10.1007/s00439-009-0722-x

[5] MUERS M. RNA Genome-wide views of long non-coding RNAs. Nature Reviews Genetics 2011; 12. http://dx.doi. org/10.1038/nrg3088 
[6] PONTING CP, OLIVER PL, REIK W. Evolution and Functions of Long Noncoding RNAs. Cell 2009; 136: 629-641. http://dx.doi.org/10.1016/j.cell.2009.02.006

[7] RINN JL, KERTESZ M, WANG JK, SQUAZZO SL, XU X et al. Functional demarcation of active and silent chromatin domains in human HOX loci by Noncoding RNAs. Cell 2007; 129: 1311-1323. http://dx.doi.org/10.1016/j.cell.2007.05.022

[8] CALIN GA, LIU CG, FERRACIN M, HYSLOP T, SPIZZO R et al. Ultraconserved regions encoding ncRNAs are, altered in human leukemias and carcinomas. Cancer Cell 2007; 12: 215-229. http://dx.doi.org/10.1016/j.ccr.2007.07.027

[9] LIN R, MAEDA S, LIU C, KARIN M, EDGINGTON TS. A large noncoding RNA is a marker for murine hepatocellular carcinomas and a spectrum of human carcinomas. Oncogene 2007; 26: 851-858. http://dx.doi.org/10.1038/ sj.onc. 1209846

[10] HIRATA H, HINODA Y, SHAHRYARI V, DENG GR, NAKAJIMA K et al. Long Noncoding RNA MALAT1 Promotes Aggressive Renal Cell Carcinoma through Ezh2 and Interacts with miR-205. Cancer Research 2015; 75: 1322-1331. http:// dx.doi.org/10.1158/0008-5472.CAN-14-2931

[11] OKUGAWA Y, TOIYAMA Y, HUR K, TODEN S, SAIGUSA $S$ et al. Metastasis-associated long non-coding RNA drives gastric cancer development and promotes peritoneal metastasis. Carcinogenesis 2014; 35: 2731-2739. http://dx.doi. org/10.1093/carcin/bgu200

[12] SUN M, JIN FY, XIA R, KONG R, LI JH et al. Decreased expression of long noncoding RNA GAS5 indicates a poor prognosis and promotes cell proliferation in gastric cancer. Bmc Cancer 2014; 14. http://dx.doi.org/10.1186/1471-2407$\underline{14-319}$

[13] SUN M, XIA R, JIN FY, XU TP, LIU ZJ et al. Downregulated long noncoding RNA MEG3 is associated with poor prognosis and promotes cell proliferation in gastric cancer. Tumor Biology 2014; 35: 1065-1073. http://dx.doi.org/10.1007/ $\underline{\text { s13277-013-1142-z }}$

[14] QI P, DU X.The long non-coding RNAs, a new cancer diagnostic and therapeutic gold mine. Modern Pathology 2013; 26: 155-165. http://dx.doi.org/10.1038/modpathol.2012.160

[15] TAKAHASHI Y, SAWADA G, KURASHIGE J, UCHI R, MATSUMURA T et al. Amplification of PVT-1 is involved in poor prognosis via apoptosis inhibition in colorectal cancers. British Journal of Cancer 2014; 110: 164-171. http://dx.doi. org $/ 10.1038 /$ bjc. 2013.698

[16] GUAN YH, KUO WL, STILWELL JL, TAKANO H, LAPUK AV et al. Amplification of PVT1 contributes to the pathophysiology of ovarian and breast cancer. Clinical Cancer Research 2007; 13: 5745-5755. http://dx.doi.org/10.1158/1078-0432. CCR-06-2882

[17] DING J, LI D, GONG MZ, WANG JP, HUANG XR et al. Expression and clinical significance of the long non-coding RNA PVT1 in human gastric cancer. Oncotargets and Therapy 2014; 7: 1625-1630. http://dx.doi.org/10.2147/OTT.S68854

[18] RISUENO A, FONTANILLO C, DINGER ME, DE LAS RIVAS J. GATExplorer: Genomic and Transcriptomic Explorer; mapping expression probes to gene loci, transcripts, exons and ncRNAs. Bmc Bioinformatics 2010; 11.
[19] PANG KC, STEPHEN S, DINGER ME, ENGSTROM PG, LENHARD B et al. RNAdb 2.0-an expanded database of mammalian non-coding RNAs. Nucleic Acids Research 2007; 35: D178-D182. http://dx.doi.org/10.1093/nar/gk1926

[20] DU Z, FEI T, VERHAAK RGW, SU Z, ZHANG Y, BROWN $M$ et al.Integrative genomic analyses reveal clinically relevant long noncoding RNAs in human cancer. Nature Structural \& Molecular Biology 2013; 20: 908. http://dx.doi.org/10.1038/ $\underline{\text { nsmb. } 2591}$

[21] LI Q, SU ZJ, XU XY, LIU GF, SONG XH et al. AS1DHRS4, a head-to-head natural antisense transcript, silences the DHRS4 gene cluster in cis and trans. Proceedings of the National Academy of Sciences of the United States of America 2012; 109: 14110-14115. http://dx.doi.org/10.1073/pnas.1116597109

[22] PASSON DM, LEE M, RACKHAM O, STANLEY WA, SADOWSKA A et al. Structure of the heterodimer of human NONO and paraspeckle protein component 1 and analysis of its role in subnuclear body formation. Proceedings of the National Academy of Sciences of the United States of America 2012; 109: 4846-4850. http://dx.doi.org/10.1073/ pnas.1120792109

[23] SRIKANTAN V, ZOU Z, PETROVICS G, XU L, AUGUSTUS $\mathrm{M}$ et al. PCGEM1, a prostate-specific gene, is overexpressed in prostate cancer. Proc Natl Acad Sci U S A 2000; 97: 1221612221. http://dx.doi.org/10.1073/pnas.97.22.12216

[24] PRENSNER JR, SAHU A, IYER MK, MALIK R, CHANDLER $B$ et al. The IncRNAs PCGEM1 and PRNCR1 are not implicated in castration resistant prostate cancer. Oncotarget 2014; 5: 1434-1438. http://dx.doi.org/10.18632/oncotarget.1846

[25] JI P, DIEDERICHS S, WANG W, BOING S, METZGER R et al. MALAT-1, a novel noncoding RNA, and thymosin beta4 predict metastasis and survival in early-stage non-small cell lung cancer. Oncogene 2003; 22: 8031-8041. http://dx.doi. org/10.1038/sj.onc. 1206928

[26] KIM K, JUTOORU I, CHADALAPAKA G, JOHNSON G, FRANK $J$ et al. HOTAIR is a negative prognostic factor and exhibits pro-oncogenic activity in pancreatic cancer. Oncogene 2013; 32: 1616-1625. http://dx.doi.org/10.1038/ onc. 2012.193

[27] XU TP, HUANG MD, XIA R, LIU XX, SUN M et al. Decreased expression of the long non-coding RNA FENDRR is associated with poor prognosis in gastric cancer and FENDRR regulates gastric cancer cell metastasis by affecting fibronectin 1 expression. J Hematol Oncol 2014; 7: 63. http://dx.doi. org/10.1186/s13045-014-0063-7

[28] SUN M, JIN FY, XIA R, KONG R, LI JH et al.Decreased expression of long noncoding RNA GAS5 indicates a poor prognosis and promotes cell proliferation in gastric cancer. BMC Cancer 2014; 14: 319. http://dx.doi.org/10.1186/14712407-14-319

[29] SUN M, XIA R, JIN F, XU T, LIU Z et al. Downregulated long noncoding RNA MEG3 is associated with poor prognosis and promotes cell proliferation in gastric cancer. Tumour Biol 2014; 35: 1065-1073. http://dx.doi.org/10.1007/s13277-0131142-Z

[30] TSENG YY, MORIARITY BS, GONG WM, AKIYAMA R, TIWARI A et al. PVT1 dependence in cancer with MYC 
copy-number increase. Nature 2014; 512: 82. http://dx.doi. org/10.1038/nature 13311

[31] HAVERTY PM, HON LS, KAMINKER JS, CHANT J, ZHANG ZM. High-resolution analysis of copy number alterations and associated expression changes in ovarian tumors. Bmc Medical Genomics 2009; 2.

[32] WANG F, YUAN JH, WANG SB, YANG F, YUAN SX et al. Oncofetal Long Noncoding RNA PVT1 Promotes Pro- liferation and Stem Cell-Like Property of Hepatocellular Carcinoma Cells by Stabilizing NOP2. Hepatology 2014; 60: 1278-1290. http://dx.doi.org/10.1002/hep.27239

[33] KONG R, ZHANG EB, YIN DD, YOU LH, XU TP et al. Long noncoding RNA PVT1 indicates a poor prognosis of gastric cancer and promotes cell proliferation through epigenetically regulating p15 and p16. Molecular Cancer 2015; 14. http:// dx.doi.org/10.1186/s12943-015-0355-8 